\title{
IL-2/9/15 Gamma Chain Receptor Inhibitor BNZ-1
}

National Cancer Institute

\section{Source}

National Cancer Institute. IL-2/9/15 Gamma Chain Receptor Inhibitor BNZ-1. NCI

Thesaurus. Code C146636.

A pegylated peptide antagonist that binds to the common gamma chain (gc; IL2RG;

CD132) of the signaling receptor for the pro-inflammatory cytokines interleukin (IL)-2, IL-

9, and IL-15, with potential immunomodulating and antineoplastic activities. Upon administration, IL-2/9/15 gc receptor inhibitor BNZ-1 specifically targets and binds to the IL binding site on the gc receptor and blocks IL-2, IL-9 and IL-15 binding, thereby inhibiting IL-2-, IL-9-, and IL-15-mediated signaling and downstream pathways. This may inhibit proliferation of tumor cells that are dependent on IL-2/9/15 signaling for their growth. IL$2 / 9 / 15$ are upregulated in certain tumor cell types and play a key role in tumor progression and survival. 